\title{
The Correlation Between Performances Among Lexical-Related Tasks and The Performance in The Sentence Construction Task
}

\section{Azwar Abidin}

Institut Agama Islam Negeri, Indonesia. E-mail: azwar.iainkendari@gmail.com

\section{ARTICLE INFO}

Keywords:

Vocabulary; Lexical decision task; Lexical Processing;

Linguistic performance;

Sentence construction

How to cite:

Abidin, A. (2021).

Proposing The Correlation

Between Performances

Among Lexical-Related

Tasks and The

Performance in The

Sentence Construction

Task. Langkawi: Journal of

The Association for Arabic

and English, 7(1), 51-65.

DOI:

http://dx.doi.org/

$\underline{10.31332 / \mathrm{lkw} . \mathrm{7i1} .2362}$

History:

Received: 2020-12-18

Accepted: 2021-06-05

Published: 2021-06-22

\begin{abstract}
This study employed a quantitative correlational design to explore the correlation between the students' performances among lexical-related tasks and how these tasks affect the performance in a sentence construction task. Using IBM SPSS Statistics Version 22's Pearson Partial Correlation Test, this study calculated participants' performance in primary lexical attributes by recognizing the following aspects of lexical knowledge: pronunciation patterns, morphological structures, syntactic properties, semantic characteristics such as abstract and interconnectedness, and a complete sentence construction in a strict naturalistic classroom setting. The test results showed that the participants made 297.05 seconds on average for 42 correct responses in Lexical Decision Task, 5.88 seconds per picture projected on the screen in Picture-Naming Task, 8.33 seconds for each word in Semantic Judgment Task, and 30.17 seconds on average to complete a sentence. These results concluded that the participants' performance in identifying strings of letters does not correlate significantly with their performance in understanding how a particular word functions grammatically within a sentence. In terms of the level of automaticity, the participants' performance exceeded the average performance. The findings suggested that their performance in understanding primary lexical attributes in single lexicons does not facilitate their understanding of semantic characteristics. Henceforth, the students' lexical knowledge does not yet construct an integrated linguistic representation in the target language acquisition. The study confirmed previous evidence that stated that a better performance in lexical-related tasks significantly impacted sentence processing and construction skill.
\end{abstract}

\section{Introduction}

Lexical knowledge assessment has a pivotal role in target language acquisition. There were many attempts to assess the students' lexical knowledge, including the vocabulary instruction which patterned students' attention on words and their uses (McKeown, 2019), the vocabulary and syntactic knowledge comparison which examined the significant predictors of the second language ability (Vafaee \& Suzuki, 2020), the assessment of both the connection and the acquisition order of multiple word knowledge components which investigated the extensive nature of vocabulary knowledge constructions (González-fernández \& Schmitt, 2020), and the identification of individual differences which determined the relation between aural vocabulary knowledge, written vocabulary knowledge, or working memory capacity in the context of pedagogical practice in second language classrooms (Masrai, 2019). These attempts were drawn to define how sufficient the words in the target language were known. It has been assumed that the significance 
of assessing the depth of lexical knowledge were generally grounded on two principles: (1) students must recognize distinct aspects of lexical knowledge and (2) students can demonstrate distinct aspects of knowledge of lexicons (Yanagisawa \& Webb, 2019). The issue suggested that understanding the students' lexical knowledge as well as their performance in lexical-related tasks must be an initial step to determine their overall performance in the target language.

Lexical knowledge represents both phonological and orthographic forms of a lexicon and attaches its syntactical properties to its potential meanings (Baayen et al., 2019). In accordance with language acquisition, lexical knowledge does have a significant role in the sentence construction skill (Schmitt \& Schmitt, 2020:27). The students who exercised better at lexical retrieval even noted a significant performance in reading comprehension and sentence construction (Ng et al., 2020:13). Proficient readers, in particular, developed the skill of paragraph building since they were sensitive to either word-level and text-level features (Ng et al., 2020:14). Lexical knowledge helps these students detect a violation in sentence coherence, suggesting an excellent sentence processing skill (Blott et al., 2020). Lexical development, which begins in infancy, facilitates a continuous acquisition of functional categories (Dye et al., 2019). These categories provide a structure for grammar organization and therefore, sentence construction. Presumably, understanding lexical knowledge is one of the most substantial phases in the target language acquisition process. It has led language teachers to realize the importance of knowing the size of a language students' vocabulary and the level of automaticity in terms of their capability in word recognition (Jiang, 2018).

In a review of studies in lexical-related tasks from the last few years, the vocabulary's size and lexical access speed were exercised occasionally with various tasks. These tasks were taken into consideration to work with different variables such as independent and source-based writing to comprehend lexical sophistication and its relation to the second language acquisition (Kyle \& Crossley, 2016), multidimensional approach tasks to predict the proficiency level in second language performance (KIM et al., 2017), a reading-based integrated task to identify the impact of textual borrowing on lexical diversity and the disparity in lexical diversity across test scores on integrated tasks (Gebril \& Plakans, 2016), a lexical tone-stress association task to determine the relationship between the joint phonological as well as acoustic processes and the lexical tone or stress perception (Choi et al., 2017), and lexical decision tasks involving both visual and auditory modalities to examine whether visual word recognition entails phonetic details during speech processing (Sauval et al., 2018). All these attempts were to retrieve the extent of measurable depth in lexical knowledge and its impacts on the target language fluency.

Lexical Decision Task (LDT) and Picture-Naming Tasks (PNT) are two of the most applied tasks to identify students' lexical knowledge in a limited time under a controlled environment. These tasks utilized word frequency (Juhasz et al., 2019) and pictures (Harvey et al., 2019) as predictors for lexical retrieval exercises. In the parallel tasks, the retrieval processes were enhanced by measuring the accuracy of coherence judgments (Maldei et al., 2019) and constructing different sentence patterns (Sun et al., 2019). The level of lexical automaticity from students' response in a given time reveals how the cognitive processes of language processing work in a 
particular condition. However, current studies have indicated that LDT and PNT were rarely exercised and other tasks that focus on identifying other lexical characteristics such as abstract and interconnectedness. Exercising lexical-related tasks with sentence construction task is even rarer. This study intended to fill that gap by exploring the correlation among performed lexical-related tasks and how those tasks correlate with the sentence construction task performance.

\subsection{Related Studies}

Matsuo (2019) investigated how proficiency levels among Japanese university students, English teachers, and English native speakers determine word recognition accuracy and fluency. This investigation revealed that reaction time and the accuracy of the lexical-decision task of the stimulus words from various word frequency levels distinguish the participants' proficiency in general. In auditory-related lexicaldecision task contexts, lexical-decision experiments in a laboratory setting are preferred. Participants' performances in terms of speed and accuracy while completing lexical-decision tasks were significantly reduced (Harker et al., 2019). Moreover, there was a notable vocal effect in spoken word recognition. A professional male actor articulated the auditory lexical-decision experiments with different acoustic vocal effects. It appeared that angry vocal effect stimulated word recognition faster than joyful and neutral effects. However, higher valence facilitated word recognition effectively than arousal, danger, and usefulness (Feeny \& Tucker, 2019).

The word frequency plays an important predictor in completing lexical decision task (Juhasz et al., 2019). This notion captures the essentiality of frequency trajectory and concludes that familiar words in childhood can be recognized and understood better in adulthood. The independence processing stages are supposedly inferred by the quality of stimulus, as an additive effect to support word frequency, into visual word recognition. Aschenbrenner and Yap (2019) examined the sensitivity of retrospective retrieval mechanism to manipulate the quality of stimulus, word frequency, and semantic priming using two lexical decision experiments and found that semantic priming can moderate the independence processing inferences.

Meaningful gestures can be used to facilitate lexical processing. However, most gesture performances shown to the participant were poorly understood to the extent that the word retrieval is not significant. However, using pictures in the naming action verb tasks, as Murteira et al. (2019) demonstrated in their study, successfully facilitated verb retrieval and supported priming in both semantic and lexical levels. Concerning semantic interference, Harvey et al. (2019) argued that naming task by displaying sequencing pictures from the same semantic category impeded subsequent naming from that category. Even though this conclusion is based on their evidence from aphasic participants, whereas semantic interference increased error rates in semantic error in the naming task, it must be considered carefully as this interference has been attributed to adjustments in the linkage between semantic and lexical representations.

Researchers believe that students can estimate the semantic coherence of highly related words in particular topics intuitively (Awwad \& Tavakoli, 2019). The present studies concluded that working memory facilitated such intuitive coherence judgments. However, Maldei et al. (2019) found that working memory load did not 
affect the intuitive coherence judgments' accuracy. Their study indicates that taxing working memory intermeddles with students' tendency to depend on their intuition. Both word association and semantic priming work effectively in an independent conscious perception setting (Avneon \& Lamy, 2019). This study implied that the time course and unconscious processes determine the quality of response priming.

The sentence construction task was designed to understand underlying activities in student's minds regarding linguistics representation. Sun et al. (2019) demonstrated how significantly different types of sentence representations could project linguistic patterns and performance differences among target language students. This demonstration provides explanation of decoded human brain activities in processing sentences instead of focusing on word-level representations. In Structured Distributional Model, semantic representation in the process of sentence construction is enhanced by understanding the context representing events and situations (Chersoni et al., 2019). The target language students must develop generalized knowledge about events that particular words are strongly attached to and store them in semantic memory. This memory plays a significant role in both sentence construction and sentence comprehension.

In children's language development, scholars believed that children rely on lexical elements to develop language comprehension. The functional elements of language, which are essential in sentence construction, develop as the lexical growth bootstraps the grammatical development. In a recent study, the functional category and lexical category have been concluded to play a foundational role in language acquisition (Dye et al., 2019). Suppose the functional category can be continuously supported by semantic judgment task in the context of lexical processing activities. In that case, this may provide a strong foundation for sentence construction and grammatical correctness.

\subsection{Literature Review}

Lexical processing is a mostly subconscious process. The student can instantly recognize a string of letters and decide whether it is a word or not regardless of what it means. Psycholinguists believe this happens because of mental lexicons a student has and stores in his or her mind (Dóczi, 2019). Each lexicon contains information attached in its lexical entry, which a student uses to identify a particular word: its spelling, pronunciation, meaning, and to which parts of speech it belongs. This lexical entry has two parts. The first is called lexeme, which addresses the form of a word, such as pronunciation and morphology. The second is called lemma, which addresses both syntactic and semantic properties of a word (Dóczi, 2019).

The lexical entry has many essential characteristics. First, it contains basic attributes of a word, such as pronunciation, morphological structures, and syntactic category (Jiang, 2018). The word book, for example, semantically means sheets of paper with written information that are bundled inside a cover and syntactically, it is a countable noun. Unlike these basics attributes, a lexical entry may also have scheming syntactic and semantic attributes and more sophisticated data such as textual or sociolinguistic context, its relevant associative words, or its connotation and denotation. Any native speaker in English knows the word fill can only be put as predicate into ground-object construction such in She fills the tumbler with water and not into figure-object 
construction as in She fills the water into the tumbler. Instead, an English native speaker would use the word pour as in figure-object construction; She pours the water into the tumbler (Ji, 2019). In addition to this explanation, any English native speaker knows semantic similarities or differences between major and main or between true and real. Such knowledge is a kind of information represented in lexical entries.

The second characteristic of the lexical entry is abstract (Jiang, 2018). It is an abstract prototype of a word that a person knows. The acoustic image of this representation can vary from one person to another depending on age, gender, dialect, or the background context in which the word appears. Native speakers often easily recognize a particular word in a natural communication despite its variation because the lexical entry they stored is highly flexible and accommodates the recognition effectively. The third characteristic is automatic (Jiang, 2018). The lexical information is retrieved automatically from a lexical entry with fewer efforts and few attentional resources. The Stroop Effect (Entel \& Tzelgov, 2019) explains that whenever a person is asked to name colors in printed words, the delay happens when the words and the colors are not consistent. This delay proves that words are recognized automatically despite the condition in which a person is asked to name only the color.

The fourth characteristic of the lexical entry is interconnectedness (Jiang, 2018). The lexical entries are interacting as well as interconnecting to each other in the lexicon. It can be seen in the neighborhood effect in word recognition as the interaction occurs when two seemingly similar words overlap (e.g., lotion, motion, notion, and potion). The interconnectedness might be semantic in nature and connects words that are tied in meaning. If a person is asked to name words that come to their mind when they hear the word big, words like small, large, or little would likely emerge as they are connected to big in meaning. The last characteristic of the lexical entry is conceptual (Jiang, 2018). The speaker builds a concept that connects the words before expressing the semantic content he or she intends to deliver. This connection develops as a child learns words and concepts together in earlier language and cognitive development. As the child gains experiences in language, this connection becomes more consolidated. The activation of this word-concept connection is automatic and bidirectional as whenever a word comes up, the concept that surrounds it becomes available right at the moment.

\section{Method}

It was a quantitative correlational study and it employed four methods of task assignments: Lexical Decision Task (LDT), Picture-Naming Task (PNT), Semantic Judgement Task (SJT), and Sentence Construction Task (SCT). These tasks were used to identify target language students' lexical decisions in a strict naturalistic classroom setting. In LDT, the participants were asked to identify a letter sequence that was displayed on the projector. The number of sequences was equal between real words and fake words in random order. The participants gave 'yes-response' if they thought the letter sequence was a word and 'no-response' if it was mistyped. In PNT, the participants were shown pictures and read aloud the names of the ones they recognized. In the SJT, the participants were to name the category of the words displayed randomly, such as 'desk' belongs to furniture category (CATSJT) and is a countable noun (POSSJT). The final task was SCT. The 
participants were given 10 (ten) words from SJT for each of them to put in to complete sentences.

\subsection{Participants of the Study}

Thirty-six first-semester students ( $N=$ twenty-eight females and eight males) from undergraduate elementary school teacher study program at a State Institute in Kendari city, Indonesia, participated in this study. All participants were EFL students and spoke Bahasa Indonesia as a Second Language fluently. By the time this study was taken, they had completed a nine-week-long course on more than 3000 words and phrases enlisted in English Vocabulary Builder Book by DK Publishing. They were also provided with informed consents in Bahasa Indonesia before beginning the experimental session.

\subsection{Instruments}

The list of vocabulary used in this study was derived from English Vocabulary Builder Book by DK Publishing. This book was selected as it was used as a primary source by the students in English 1 subject. Before performing lexical-related tasks, this book was taught and exercised in 24 hours and 75 minutes in total from a nine-week intensive course. The average length of each displayed string was 7.2 letters for both words and mistyped word stimuli. There were 50 letter sequences in Lexical Decision Task (LDT) with 25 sequences, and 25 others were non-words. There were 50 images displayed in Picture-Naming Task (PNT) with 25 images for noun words and 25 others for verb phrases. In both Semantic Judgement Task (SJT), 30 closely related words were displayed and 10 from these words were randomly selected for the participants to put into complete sentences in Sentence Construction Task (SCT).

\subsection{Data Analysis Procedures}

This study investigated participants' performance in lexical entry basic attributes by recognizing pronunciation pattern, morphological structure, syntactic property, semantic characteristics such as abstract and interconnectedness, and constructing complete sentences using IBM SPSS Statistics Version 22's Pearson Partial Correlation Study.

\section{Findings and Discussion}

These tasks were performed in a classroom setting. The participants interchangeably stepped in one by one while the rest waited for their turn outside the classroom. Each session carried one particular task and it was performed in a week interval. Each session also varied in terms of timing. Both Lexical Decision Task (LDT) and Picture-Naming Task (PNT) took 300 seconds to complete. Semantic Judgement Task (SJT) took 250 seconds, while Sentence Construction Task (SCT) only took 200 seconds. LDT was meant to exercise participants' knowledge of lexical entry basic attributes by recognizing pronunciation patterns and morphological structure from string of letters presented on screen. PNT focused on identifying syntactic attributes in particular. SJT explored participants' knowledge of other lexical characteristics such as abstract and interconnectedness.

In LDT, the participants identified both $84 \%$ words and non-words on average. These total 42 correct responses were given on average 297.05 seconds. That 
makes around 7.13 seconds per correct response and around 7.91 per incorrect response. In total, it took 5.94 seconds for each string of letters. In sum, the participants identified $84.16 \%$ of both real and false words from $99.04 \%$ from elapsed seconds. In PNT, the participants identified $80.5 \%$ of the given stimulus correctly in 294 seconds on average. That makes about 5.88 seconds per picture projected on the screen. In total, they named $88.44 \%$ nouns, $72.6 \%$ verbs, and $19.5 \%$ incorrect answers on average.

In the SJT, the participants gave 39.1\% correct responses in the word category section and $67.2 \%$ correct responses in the part of speech section from the total 150 minutes (9000 seconds) or 250 seconds for each participant. So, the total response time for each word is 8.33 seconds on average. In SCT, each participant made around 6 or 7 sentences and each sentence took around 30.17 seconds to complete. Overall, each participant needs 3.33 minutes (200 seconds) to give 6 or 7 complete sentences. Table 1 shows the distribution of both correct and incorrect responses given by the participants along with the seconds spent in the process:

Table 1. Distribution of correct/ incorrect responses from all tasks

\begin{tabular}{|c|c|c|c|c|c|c|c|c|}
\hline \multirow{3}{*}{ Tasks } & \multirow{3}{*}{$\begin{array}{l}\text { SoLs } \% \\
\text { Words }\end{array}$} & \multicolumn{6}{|c|}{ Responses } & \multirow{3}{*}{$\begin{array}{c}\text { TRT }^{*} \\
\text { In Seconds } \\
\text { In Average }\end{array}$} \\
\hline & & \multicolumn{3}{|c|}{ Correct } & \multicolumn{3}{|c|}{ Incorrect } & \\
\hline & & Max & Mean & Min & Max & Mean & Min & \\
\hline \multicolumn{8}{|l|}{ Lexical Decision (LD) } & 297,05 \\
\hline Words & 25 & 25 & 21 & 16 & 9 & 4 & 0 & 5,94 \\
\hline Non-Words & 25 & 25 & 21 & 16 & 9 & 4 & 0 & per SoLs \\
\hline \multicolumn{8}{|l|}{ Picture-Naming (PN) } & 294 \\
\hline Nouns & 25 & 25 & 22,07 & 18 & 7 & 2,9 & 0 & 5,88 \\
\hline Verbs & 25 & 22 & 18,15 & 15 & 10 & 7 & 3 & per Word \\
\hline \multirow{3}{*}{\multicolumn{2}{|c|}{$\begin{array}{l}\text { Semantic Judgment (SJ) } \\
\text { Word Category (CATSJ) } \\
\text { Part of Speech (POSSJ) }\end{array}$}} & & & & & & & 250 \\
\hline & & 25 & 9,8 & 7 & 23 & 20 & 15 & 8,33 \\
\hline & & 20 & 16,7 & 13 & 17 & 13,2 & 10 & per Word \\
\hline \multicolumn{2}{|l|}{ Sentence Construction (SC) } & & & & & & & 200 \\
\hline Completed Sentences & 10 & 9 & 6,63 & 4 & - & - & - & $\begin{array}{c}30,17 \\
\text { per Sentence }\end{array}$ \\
\hline \multirow{4}{*}{ Total Participants: 36} & $\begin{array}{l}{ }^{\circ} \text { SoLs: } \\
\text { Letters }\end{array}$ & \\
\hline & $: L D \mathcal{E} P N$ & \multicolumn{7}{|c|}{$\begin{array}{l}\text { String of } \\
{ }^{*} \text { TRT: Total Response Time } \\
\text { J: } 180 \text { minutes (5 minutes/ participant) }\end{array}$} \\
\hline & $S J$ & \multirow{2}{*}{\multicolumn{7}{|c|}{$\begin{array}{l}\text { : } 150 \text { minutes ( } 4.17 \text { minutes/ participant } \\
: 120 \text { minutes ( } 3.33 \text { minutes/ participant) }\end{array}$}} \\
\hline & $S C$ & & & & & & & \\
\hline
\end{tabular}

Source: Data Findings, 2019

Basically, LDT and PNT were seeking a clear description of participants' knowledge of the lexical entry by determining basic attributes of projected string of letters/ words on screen. Using SPSS Pearson Partial Correlation test, the results 
from these two tasks were averagely significant. Table 3 as test results shows that recognizing patterns of pronunciation and morphological structures from projected string of letters, as intended in LDT, may better identify syntactic attributes of words that pictures in PNT referred to.

Table 2. Descriptive statistics of the test results.

\begin{tabular}{lcll}
\hline \multicolumn{2}{l}{ Descriptive Statistics } & & \\
\hline \multirow{2}{*}{ LDT } & Mean & Std. Deviation & $N$ \\
& 42,0833 & 4,48091 & 3 \\
PNT & 40,2500 & 2,40684 & 6 \\
& & & 3 \\
CATSJT & 9,7778 & 2,42736 & 6 \\
& & & 3 \\
POSSJT & 16,8056 & 1,90967 & 6 \\
& & & 3 \\
SCT & 6,6389 & 1,33423 & 6 \\
& & & 6 \\
\hline
\end{tabular}

Source: Data Findings, 2019

The next values explained how recognizing and identifying lexical entry basic attributes contributes to understanding lexical characteristics such as abstraction and interconnectedness by identifying the word category and parts of speech. The SJT task results, as shown in Table 1, show the participants identified Parts of Speech (POSSJT), of which a particular word belongs, better than identifying that word category (CATSJT). Participants' ability to perform well in both LDT and PNT seems to not correlate with their performance in CATSJT. The LDT $r$ value is 0,233 ; with $p$ value $0.172>0.05$ and PNT $r$ value is 0.291 ; with $p$ value $0.291>0.05$ indicated there were no significant correlation between the ability to identify letter of strings/ words with the ability to explain word category. Instead, both LDT and PNT show significant correlation with POSSJT whereas LDT $r$ value is 0.843 ; with $p$ value $0.000<0.05$ and PNT $r$ value is 0.415 ; with $p$ value $0.012<0.05$. The ability to identify string of letters / words correlates with the ability to understand how a particular word function grammatically. CATSJT does not even correlate, in general, with any other variables except POSSJT.

SCT has an interesting case in particular. Although its significance values in correlation with other variables show no positive effects, considering the Pearson partial correlation test results, its role as a control variable does contribute a significant effect to facilitate the correlation among independent variables. The correlation values between independent variables increase with SCT as dependent variable. Participants' performance in sentence construction seems to enhance participants' current pattern recognition skill in identifying syntactic attributes of a word and determining parts of speech. SCT performance also affects participants' syntactic attribute identification skills positively when deciding which parts of speech category a word belongs to. 
Table 3. Pearson partial correlation test results.

\begin{tabular}{|c|c|c|c|c|c|c|c|}
\hline \multicolumn{8}{|c|}{ Correlations } \\
\hline \multicolumn{3}{|c|}{ Control Variables } & LDT & PNT & CATSJ & POSSJ & SCT \\
\hline \multirow[t]{15}{*}{$\begin{array}{l}\text {-none- } \\
\text { a }\end{array}$} & LDT & Correlation & $\begin{array}{l}1,00 \\
0\end{array}$ &, 512 & 233 & 843 & , 125 \\
\hline & & Significance (2-tailed) & . & ,001 & 172 & ,000 & ,469 \\
\hline & & Df & 0 & 34 & 34 & 34 & 34 \\
\hline & PNT & Correlation &, 512 & $\begin{array}{l}1,00 \\
0\end{array}$ & 181 & ,415 & 171 \\
\hline & & Significance (2-tailed) & ,001 & . & 291 & ,012 & 318 \\
\hline & & Df & 34 & 0 & 34 & 34 & 34 \\
\hline & CATSJT & Correlation & 233 & 181 & 1,000 & ,342 & $\begin{array}{l}- \\
, 123\end{array}$ \\
\hline & & Significance (2-tailed) & 172 & 291 & . & ,041 & 477 \\
\hline & & Df & 34 & 34 & 0 & 34 & 34 \\
\hline & POSSJT & Correlation & ,843 & ,415 & ,342 & 1,000 & $\begin{array}{l}- \\
, 073\end{array}$ \\
\hline & & Significance (2-tailed) & ,000 & ,012 & ,041 & . & 671 \\
\hline & & Df & 34 & 34 & 34 & 0 & 34 \\
\hline & SCT & Correlation & 125 & 171 &,- 123 &,- 073 & $\begin{array}{l}1,00 \\
0\end{array}$ \\
\hline & & Significance (2-tailed) & ,469 & ,318 & ,477 & 671 & . \\
\hline & & Df & 34 & 34 & 34 & 34 & 0 \\
\hline \multirow[t]{12}{*}{ SCT } & LDT & Correlation & $\begin{array}{l}1,00 \\
0\end{array}$ &, 502 & ,252 & ,861 & \\
\hline & & Significance (2-tailed) & . & ,002 & 144 & ,000 & \\
\hline & & Df & 0 & 33 & 33 & 33 & \\
\hline & PNT & Correlation & ,502 & $\begin{array}{l}1,00 \\
0\end{array}$ & 207 & ,435 & \\
\hline & & Significance (2-tailed) & ,002 & . & ,234 & ,009 & \\
\hline & & Df & 33 & 0 & 33 & 33 & \\
\hline & CATSJT & Correlation & ,252 & ,207 & 1,000 & ,336 & \\
\hline & & Significance (2-tailed) & 144 & ,234 & . & ,048 & \\
\hline & & $\mathrm{df}$ & 33 & 33 & 0 & 33 & \\
\hline & POSSJT & Correlation & ,861 & ,435 & ,336 & 1,000 & \\
\hline & & Significance (2-tailed) & ,000 & ,009 & ,048 & . & \\
\hline & & $\mathrm{df}$ & 33 & 33 & 33 & 0 & \\
\hline
\end{tabular}

a. Cells contain zero-order (Pearson) correlations.

Source: Data Findings, 2019 
In terms of the participants' level of automaticity shown in their task performance, as concluded in Table 1, the results are quite appealing. On average, they performed better than expected. Both in LDT and PNT, the target was 6 seconds per string of letters or words. Surprisingly, they noted 5.94 seconds per string of letters in LDT and 5.88 seconds per word in PNT. In SJT, all participants spent 8.33 seconds per word, which is normal as each of them had around 4.16 minutes to spend. However, their performance dropped when asked to put words into sentences. In SCT, they were required to construct a sentence in no less than 20 seconds. Unfortunately, the average elapsed seconds the participants need to perform this task were 30.17 seconds per sentence. This finding seemed to correlate with participants' performance in CATSJT. These two cases proved that the participants performed poorly in sentence-related tasks.

\subsection{Pattern recognition in LDT and PNT}

Matsuo (2019) measures the students' proficiency level by assuming their accuracy in LDT performance from the reaction time. In this study, the participants made lexical judgments faster than expected. However, this study excluded some essential factors such as environment's noise level, audio representations from different voices, and misspelled word variances that significantly affected task performance (Feeny \& Tucker, 2019). Instead, there was an important factor that seems to contribute to participants' overall performance; the predictors. Basically, Harvey et al. (2019) consider predictors as an important memory retrieval facility when the students are making lexical decisions in the target language. These predictors are usually familiar words derived from childhood memory which were frequently used in any activity. Word frequency, of which its frequency trajectory is predisposed by word occurrence in childhood, is an influential predictor of LDT performance. Juhasz et al. (2019) found that the age at which a word is acquired for the first time and its frequency trajectory crosswise childhood memory affected performance in LDT significantly.

This study simulated those frequency trajectories by preparing the participants through nine-week intensive vocabulary training. The basic assumption came from the previous hypothesis that the more familiar the concept related to the words; the smoother memory retrieval would be. This assumption also supports the similarity hypothesis that explains participants' well performance in LDT. Using an experimental study on a two-string LDT between fake words and real words, Zhang \& Zhang (2019) concluded that the participants incline to give faster responses to fake words that sound like real words than fake words that look like real words. If the words are strongly related, the participants responded slower to fake words, whether they looked like or sounded like. This study did not explore such significant features as the string of letters and words were put randomly to the list without considering their similarities. However, since the participants were assumed, based on the test results, to perform better in LDT and PNT because they recognized pronunciation pattern and morphological structure from string of letters or words presented on screen. Thus, the similarity is recognized solely from the pattern and the similarity in concept needs to be explored in further study. 


\subsection{Comparative analysis from lexical performance to sentence construction}

Words have been reasoned to be cognitively simpler than sentences. Words, on the one hand, have limited models as linear strings of morphemes. Sentences, on the other hand, typify hierarchy in syntactic structure. However, Oseki et al. (2019) found that the participants' morphological pattern recognition identifies morphemes increased gradually from left to right and dissects them into hierarchical syntactic structures. This finding does not correlate with the linear string model of morphemes. In this study, the participants seem to rely on native-to-target words direct translation in processing comprehension cognitively. However, this process becomes more difficult when translating phrases or clauses as it requires understanding semantic coherence by determining highly related words in both native and target language. In LDT, PNT, and POSSJT, the participants were expected to respond only with a single word. In LDT, the only response they were asked to give was yes-no response. In CATSJT, they need to think of a word in a particular context before responding by mentioning that word's category. Giving response by mentioning furniture for chair, as an example, the participants need to recognize the concept of furniture which chair has any characteristic of being categorized into. The participants could not complete this task excellently because they were not used to doing such a cognitively demanding event in the unconscious process.

Semantic representations depend on the quality of response priming. This requires downloading highly related words from the working memory. In a limited time, the participants seemed to choose to skip the task to construct semantic coherence from presented words as they prefer to complete the easier challenge. Moreover, Gilbert et al. (2019) look into the consequence of altering the position of the unclouded context and comprehension task on the word-meaning priming effect. The results demonstrated that priming could occur for both subsequent disambiguation sentence type and interpretation of unprimed ambiguous words type. This finding hinted that the participants' final version of the word meanings during the prime stumble drove their form of acquisition despite the earliest misinterpretation. However, the prime conditions made the egression of priming for subsequent disambiguation sentences more sensitive. Whenever the task may conceivably be carried out without the need to make another analysis of the ambiguity, it means that no significant priming was considered. Participants' poor performance in SJT verifies this phenomenon. In this task, they were asked not only to determine the grammatical function of presented words but also to mention the words' category. This underachieved performance revealed that the participants failed to notice the ambiguity they made when connecting words to their attached category. Even though CATSJT performance correlates with POSSJT significantly, that performance did not correlate with other variables. Even though Harvey et al. (2019) found that PNT performance helps students to complete category-naming task, this study found that the participants excelled in PNT, but this excellence did not contribute to their category-naming performance at all.

SCT, in particular, demands a better performance in SJT. As both CATSJT and POSSJT did not show any significant correlation to SCT in this study, the participants struggled to make sentences out of 10 words previously exercised along with 20 
other words in SJT. SCT explains the linguistic representation in cognitive processes. It also helps to identify how well the students understand the context from which a lexicon appears. That means the students need to be familiar with the events and situation, whereas attached lexicons from semantic memory can be both relevant and coherent to be used. The findings supported the evidence which stated that a better performance in lexical knowledge, particularly understanding syntactic and semantic properties, did have a significant impact on sentence construction skills (Schmitt \& Schmitt, 2020), reading comprehension (Ng et al., 2020), and detecting violations in the sentence coherence (Blott et al., 2020). Literal translation, which stresses lexeme as input for lexical entry, may help students recognize new patterns as an initial step to learn new words from the target language. However, significant vocabulary acquisition is only possible whenever the students understand how the lemma works. As this study suggested, literal vocabulary acquisition helps in better performances at recognizing lexicons as separate items, but only conceptual vocabulary acquisition grants an acceptable skill in the target language's sentence construction.

\section{Conclusion}

Based on Pearson partial correlation test in this study, the participants' performance in SCT did not correlate with other lexical-related performances. Although they excelled in single-lexicon-related tasks, they underachieved in sentence-related tasks. Furthermore, their ability to recognize basic lexical attributes in single lexicons does not facilitate their understanding of semantic characteristics such as abstract and interconnectedness. Therefore, the students' lexical knowledge does not yet construct an integrated linguistic representation in the target language acquisition. This study suggests more varied lexical-related tasks implementation as it limited to a strict naturalistic classroom setting. It also suggests longer material adaptations and repeated assessments as this study only prepared a nine-week course on essential vocabularies for the participants and a one-time chance to perform in each of lexical-related tasks and the sentence construction task.

\section{References}

Aschenbrenner, A. J., \& Yap, M. J. (2019). The influence of relatedness proportion on the joint relationship among word frequency, stimulus quality, and semantic priming in the lexical decision task. Quarterly Journal of Experimental Psychology. https://doi.org/10.1177/1747021819845317

Avneon, M., \& Lamy, D. (2019). Do semantic priming and retrieval of stimulusresponse associations depend on conscious perception? Consciousness and Cognition. https://doi.org/10.1016/j.concog.2019.01.010

Awwad, A., \& Tavakoli, P. (2019). Task complexity, language proficiency and working memory: Interaction effects on second language speech performance. International Review of Applied Linguistics in Language Teaching. https://doi.org/https://doi.org/10.1515/iral-2018-0378

Blott, L., Rodd, J., Ferreira, F., \& Warren, J. (2020). Recovery from misinterpretations during online sentence processing. Journal of Experimental Psychology: Learning, Memory, and Cognition. https://doi.org/10.31234/osf.io/3ejqy

Chersoni, E., Santus, E., Pannitto, L., Lenci, A., Blache, P., \& Huang, C. R. (2019). A structured distributional model of sentence meaning and processing. Natural 
Language Engineering. https:/ / doi.org/10.1017/S1351324919000214

Choi, W., Tong, X., \& Singh, L. (2017). From lexical tone to lexical stress: A crosslanguage mediation model for cantonese children learning English as a second language. Frontiers in Psychology. https://doi.org/10.3389/fpsyg.2017.00492

Dóczi, B. (2019). An Overview of Conceptual Models and Theories of Lexical Representation in the Mental Lexicon. In The Routledge Handbook of Vocabulary Studies. https:/ / doi.org/10.4324/9780429291586-4

Dye, C., Kedar, Y., \& Lust, B. (2019). From lexical to functional categories: New foundations for the study of language development. First Language. https://doi.org/10.1177/0142723718809175

Entel, O., \& Tzelgov, J. (2019). When Working Memory Meets Control in the Stroop Effect. Journal of Experimental Psychology: Learning Memory and Cognition. https://doi.org/10.1037/xlm0000790

Feeny, G. T., \& Tucker, B. V. (2019). Emotion and Lexical Effects in an Auditory Lexical Decision Task With Vocal Affect. Education and Research Archive University of Alberta. https:/ / doi.org/https:/ /doi.org/10.7939/r3-fn84-db59

Gebril, A., \& Plakans, L. (2016). Source-based tasks in academic writing assessment: Lexical diversity, textual borrowing and proficiency. Journal of English for Academic Purposes. https:/ / doi.org/10.1016/j.jeap.2016.10.001

González-fernández, B., \& Schmitt, N. (2020). Word Knowledge: Exploring the Relationships and Order of Acquisition of Vocabulary Knowledge Components. Applied Linguistics. https://doi.org/10.1093/applin/amy057

Harald Baayen, R., Chuang, Y. Y., Shafaei-Bajestan, E., \& Blevins, J. P. (2019). The Discriminative Lexicon: A Unified Computational Model for the Lexicon and Lexical Processing in Comprehension and Production Grounded Not in (De)Composition but in Linear Discriminative Learning. Complexity. https://doi.org/10.1155/2019/4895891

Harker, B., Leung, M., Fonseca, D., Halfyard, S., Sinclair, M., \& May, S. (2019). Massive Auditory Lexical Decision: Investigating Performance in Noisy Environments. Education and Research Archive University of Alberta, 2-5. https://doi.org/https://doi.org/10.7939/r3-hrnv-sn79

Harvey, D. Y., Traut, H. J., \& Middleton, E. L. (2019). Semantic interference in speech error production in a randomised continuous naming task: evidence from aphasia. Language, Cognition and Neuroscience. https://doi.org/10.1080/23273798.2018.1501500

Ji, Y. (2019). Chapter 10. Linguistic and mental representations of caused motion in Chinese and English children. https://doi.org/10.1075/hcp.67.12ji

Jiang, N. (2018). Second Language Processing: An Introduction. Taylor \& Francis. https:/ / books.google.co.id/books?id=-xZSDwAAQBAJ

Juhasz, B. J., Yap, M. J., Raoul, A., \& Kaye, M. (2019). A further examination of word frequency and age-of-acquisition effects in English lexical decision task performance: The role of frequency trajectory. Journal of Experimental Psychology: Learning Memory and Cognition. https://doi.org/10.1037/xlm0000564

KIM, M., CROSSLEY, S. A., \& KYLE, K. (2017). Lexical Sophistication as a Multidimensional Phenomenon: Relations to Second Language Lexical Proficiency, Development, and Writing Quality. The Modern Language Journal, 
102(1), 120-141. https://doi.org/10.1111/modl.12447

Kyle, K., \& Crossley, S. (2016). The relationship between lexical sophistication and independent and source-based writing. Journal of Second Language Writing. https://doi.org/10.1016/j.jslw.2016.10.003

Maldei, T., Koole, S. L., \& Baumann, N. (2019). Listening to your intuition in the face of distraction: Effects of taxing working memory on accuracy and bias of intuitive judgments of semantic coherence. Cognition. https://doi.org/10.1016/j.cognition.2019.05.012

Masrai, A. (2019). Exploring the impact of individual differences in aural vocabulary knowledge, written vocabulary knowledge and working memory capacity on explaining L2 learners' listening comprehension. Applied Linguistics Review. https:/ / doi.org/10.1515/applirev-2018-0106

McKeown, M. G. (2019). Effective Vocabulary Instruction Fosters Knowing Words, Using Words, and Understanding How Words Work. Language, Speech, and Hearing Services in Schools, 50(4), 466-476. https:/ / doi.org/10.1044/2019_LSHSSVOIA-18-0126

Murteira, A., Sowman, P. F., \& Nickels, L. (2019). Taking action in hand: effects of gesture observation on action verb naming. Language, Cognition and Neuroscience. https://doi.org/10.1080/23273798.2018.1552978

Ng, S., Payne, B. R., Liu, X., Anderson, C. J., Federmeier, K. D., \& Stine-Morrow, E. A. L. (2020). Execution of Lexical and Conceptual Processes in Sentence Comprehension among Adult Readers as a Function of Literacy Skill. Scientific Studies of Reading, 24(4), 338-355. https://doi.org/10.1080/10888438.2019.1671849

Oseki, Y., Yang, C., \& Marantz, A. (2019). Modeling Hierarchical Syntactic Structures in Morphological Processing. https://doi.org/10.18653/v1/w19-2905

Rebecca Gilbert, Matthew Davis, M. Gareth Gaskell, \& Jennifer Rodd. (2019). Sentence structure and listening task affect the retuning of lexical-semantic representations. https://doi.org/10.31234/osf.io/qvaud

Sauval, K., Perre, L., \& Casalis, S. (2018). Phonemic feature involvement in lexical access in grades 3 and 5: Evidence from visual and auditory lexical decision tasks. Acta Psychologica. https://doi.org/10.1016/j.actpsy.2017.12.002

Schmitt, N., \& Schmitt, D. (2020). Vocabulary in Language Teaching. Cambridge University Press. https:/ / books.google.co.id/books?id=jILoDwAAQBAJ

Sun, J., Wang, S., Zhang, J., \& Zong, C. (2019). Towards Sentence-Level Brain Decoding with Distributed Representations. Proceedings of the AAAI Conference on Artificial Intelligence. https:// doi.org/10.1609/aaai.v33i01.33017047

Tohru Matsuo. (2019). Measuring Japanese Learners' Lexical Accuracy and Fluency Using A Lexical Decision Task. Departmental Bulletin Paper.

Vafaee, P., \& Suzuki, Y. (2020). THE RELATIVE SIGNIFICANCE OF SYNTACTIC KNOWLEDGE AND VOCABULARY KNOWLEDGE IN SECOND LANGUAGE LISTENING ABILITY. Studies in Second Language Acquisition, 42(2), 383-410. https:// doi.org/10.1017/S0272263119000676

Yanagisawa, A., \& Webb, S. (2019). Measuring Depth of Vocabulary Knowledge. The Routledge Handbook of Vocabulary Studies, 371-386. https://doi.org/10.4324/9780429291586-24 
Zhang, S., \& Zhang, S. (2019). Experimental Study on a Two-string Lexical Decision Task: Non-Words and Words. International Journal of Recent Contributions from

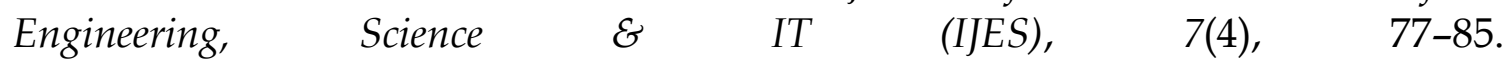
https://onlinejour.journals.publicknowledgeproject.org/index.php/ijes/article/viewFile/11715/6227 